\title{
Comparative Study of an Augmented Reality Software Development Kit Suitable for Forensic Medicine Education
}

\author{
Krittiyaporn Tongprasom, Wanwanut Boongsood, Woramon Boongsood, and Tossanai Pipatchotitham
}

\begin{abstract}
In the process of creating an Augmented Reality (AR) system, there are various Augmented Reality Software Development Kits (AR SDK) available for development. Each AR SDK has different features. Therefore, a study has to be performed about which AR SDK is appropriate for implementation. This paper focuses on an AR system for Forensic Medicine education in Thailand, where drowning is one of the main causes of death. With the aim of a comparative study and selection, the AR SDK type suitable for use in creating an AR system for teaching Forensic Medicine is selected. The traditional teaching and learning method was studied. There were general requirements of SDKs which are recognition of objects in both $2 \mathrm{D}$ and $3 \mathrm{D}$, recognition stability of immovable and movable markers, and supporting platforms both Android and iOS. It was found that Vuforia is an AR SDK suitable for use in Forensic Medicine education. Studying and comparing the various Vuforia feature types resulted in the image target and model target as appropriate methods for Forensic Medicine education in the case of investigating drowning.
\end{abstract}

Index Terms-AR technology, SDK, drowning, forensic study, criminal procedural law, crime.

\section{INTRODUCTION}

According to the code of criminal procedural law section 150 [1] in the case of requiring postmortem examination, inquiry officials and a forensic physician can perform a postmortem examination. But if at the time a forensic physician is not available a general practitioner can perform the postmortem. The general practitioner must be able to perform a postmortem examination.

According to medical competency assessment criteria for national license 2012 [2], a medical professional must be able to perform a postmortem examination and collect evidence as required by law together with the inquiry official. Therefore, forensic medicine is included in the medical curriculum.

Forensic medicine is a required subject in the Doctor of Medicine Program [3]. According to Black's Law Dictionary, forensic medicine is "That science which teaches the application of medical knowledge to the purpose of law" [4].

Manuscript received May 3, 2020; revised October 26, 2020. This work was supported in part by Suranaree University of Technology, Thailand.

K. Tongprasom and W. Boongsood are with the School of Manufacturing Engineering, Suranaree University of Technology, Nakhon Ratchasima, 30000, Thailand (e-mail: krittiyaporn014@gmail.com, wanwanut@sut.ac.th).

W. Boongsood is with Thammasat University Hospital, Pathum Thani, 12120, Thailand (e-mail: wboong@tu.ac.th).

T. Pipatchotitham is with the Faculty of Medicine, Thammasat University, Pathum Thani, 12120, Thailand (e-mail: tossanai.pip@gmail.com).
The practical study of forensic medicine is current in Thailand [3], where 5th-year medical students must follow a medical professor to the postmortem examination at an actual crime scene investigation. This method has limitations in that it cannot be repeated, one cannot determine the crime scene that you want to study, and there are few crime scenes to study. To solve this problem, the Faculty of Medicine, Thammasat University, uses a passive mannequin and creates simulation crime scenes [5]. However, this method still has limitations: to change the case study, a new simulation is needed, and it is complicated. Therefore, in the study of postmortem examination methods, there must be simulations that help the students visualize more clearly and have the correct techniques to guide students to follow.

Currently, there is a technology that can augment information and imagery into a real-world environment, called Augmented Reality (AR) technology. AR enhances a user's perception of and interaction with the real world. The virtual objects display information that the user cannot directly detect with their own senses. AR technology is being applied in various fields, including medicine [6], industrial [7], and education [8].

Professionals and researchers have striven to study a systematic review of the advantages and challenges augmented reality for education. The most-reported power of AR is that promoting academic achievement and difficulty of implementing AR is usability and technical problems [9]. For example, one shows an AR view of a student examining an augmented 3D model of a camshaft arrangement, in conjunction with a set of real engine components [10]. This research demonstrates that $\mathrm{AR}$ can make complicated mechanisms and difficult theories in higher education easier, since students can explore a 3D visualization of the teaching material, thus enabling them to understand more effectively through interactivity with multimedia content.

But to develop a stable AR application one needs to select a suitable development tool or Software Development Kit (SDK) to build a database with high quality and to optimize feature recognition. For example, an AR system for teaching hand-drawn mechanical drawing [11]. This system was developed using the ARToolKit SDK which overlays a mechanical 3D object recognized onto a cubic AR marker. Users can watch 3D objects in various aspects like the front, back, top, bottom, left and right through rotating the cubic AR marker. There is also a using AR system jointly UAVs (Unmanned Aerial Vehicles) to explore archaeological sites that are not often directly accessible from the user [12]. This work is the development of a location-based AR Android 
application using the Wikitude SDK framework that produces $3 \mathrm{D}$ models and textual information directly on the archaeological sites. An AR system for superimposing 3D animal models on user-defined targets has been produced [13]. The system is designed to superimpose a 3D animal model living in Thailand over user-defined target using Vuforia SDK, which is based on a computer vision algorithm to process from camera images in real-world and superimpose $3 \mathrm{D}$ content on those images in real-time.

We studied SDK types suitable for forensic medicine education following the flowchart in Fig. 1. This paper is organized as follows. Section II describes the AR SDKs for iOS and Android development, the different type of features of the selected SDK platforms in section III, and the current methods of forensic medicine education with the case study of drowning in section IV. Comparison of the requirements of forensic medicine education drowning case studies with the features of the selected SDK is in section V. Section VI is the results and discussion, and finally we give conclusions of the results.

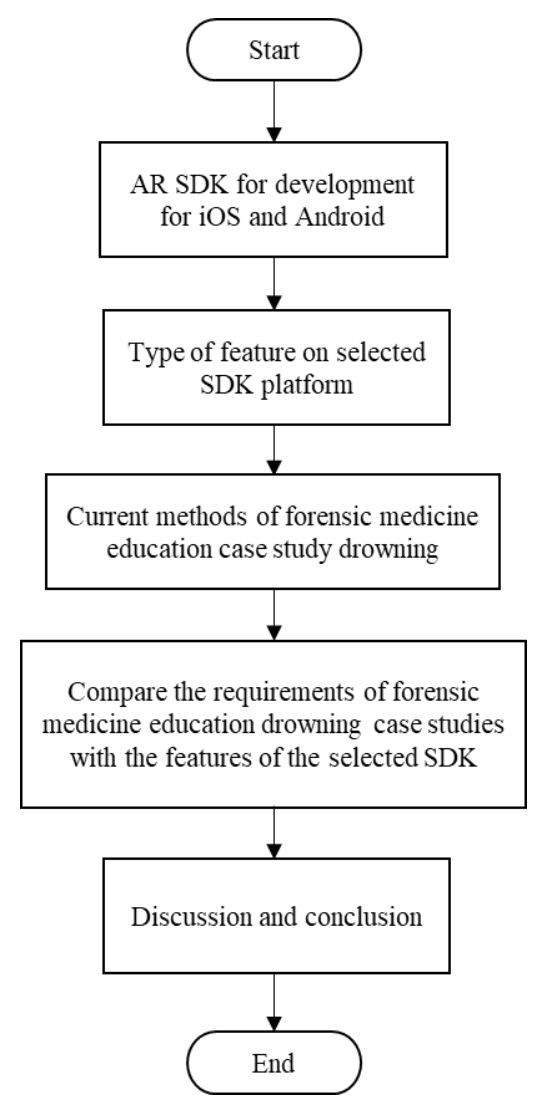

Fig. 1. Flowchart for study of an SDK type suitable for forensic medicine education.

\section{AugMENTED REALITY SDK FOR DEVELOPMENT}

Generally, there are two types of AR, marker-based and marker-less AR [14]. Marker-based uses a 2D marker to determine the position of the AR information, which means that the camera must perceive a specific visual cue for the software to call up the correct information. In another direction, marker-less is designed without the need for a $2 \mathrm{D}$ marker or reference points but needs a tracking system that involves GPS (Global Positioning System), a compass, or an image recognition device. To develop a stable AR application, we need to select a proper development tool to build a database with high quality and optimized feature recognition.

An AR Software Development Kit (AR SDK) is a development tool for AR applications that facilitates many features such as $\mathrm{AR}$ recognition, AR tracking, and $\mathrm{AR}$ content rendering. AR recognition works as the brain of the AR system. AR tracking works as the eyes of the AR system, and $\mathrm{AR}$ content rendering is similar to imagining virtual objects. But the use of AR for teaching in forensic medicine has specific requirements and the SDK to be used for application development must have a variety of features. Therefore, it is necessary to study appropriate methods.

AR SDK is a development tool for AR applications that facilitates many features such as $A R$ recognition, $A R$ tracking, and AR content rendering [15]. AR recognition works as the brain of the AR system. AR tracking works as the eyes of the AR system, and AR content rendering is similar to imagining virtual objects. There are various SDKs for developers to build AR applications in the most efficient manner. The best AR SDKs for development on iOS and Android in 2019 include 9 SDKs [16].

For this paper, there is a general requirement in forensic medicine used in screening for an SDK that it has 1) both 2D and $3 \mathrm{D}$ object recognition, 2) has recognition stability of immovable markers and 3) movable markers, and 4) both Android and iOS are supported platforms. From Table I, requirement 1 is it must recognize objects in both $2 \mathrm{D}$ and $3 \mathrm{D}$ because the database in this research is a mannequin. Next requirements 2 and 3 are recognition stability of immovable markers and movable markers, respectively, because in the process of detecting objects, the mannequin will not be moving but will move when being turned over. Finally, requirement 4 is that it must be a platform that can support both Android and iOS.

TABLE I: SDK COMPARISON BASED ON THE REQUIREMENTS OF FORENSIC MEDICINE STUDIES

\begin{tabular}{l|l|c|c|c}
\hline \multirow{2}{*}{$\begin{array}{c}\text { SDK for } \\
\text { development }\end{array}$} & \multicolumn{4}{c}{ Requirement } \\
\cline { 2 - 5 } \multicolumn{1}{c}{$\mathbf{1}$} & $\mathbf{2}^{*}$ & $\mathbf{3}^{*}$ & $\mathbf{4}$ \\
\hline Wikitude & 2D, 3D & 6 & 6 & iOS, Android \\
\hline ARKit & 2D, 3D & 9 & 7 & iOS \\
\hline ARcore & 2D, 3D & 9 & 6 & iOS, Android \\
\hline Vuforia & 2D, 3D & 10 & 6 & iOS, Android \\
\hline MaxST & 2D, 3D & 7 & 2 & iOS, Android \\
\hline DeepAR & 2D & 8 & 7 & iOS, Android \\
\hline EasyAR & 2D & 7 & 3 & iOS, Android \\
\hline ARToolKit & 2D & 8 & 6 & iOS, Android \\
\hline Xzimg & 2D & 4 & 3 & iOS, Android \\
\hline \hline
\end{tabular}

*Recognition stability of immovable and movable markers uses values from ThinkMobiles [16].

We chose the Vuforia SDK due to this SDK being able to detect both 2D and 3D objects, having more recognition stability of immovable markers than other SDKs, and supporting both Android and iOS platforms.

\section{VUforia ENGINE FEATURES}

Vuforia Engine's recognition and tracking capabilities can support different types of targets, both $2 \mathrm{D}$ and $3 \mathrm{D}$, including 
multi-target configurations, cylinder targets to track images on a cylindrical surface, object targets with both small and large objects. It also supports the detection and tracking of horizontal surfaces, enables digital content to be placed on horizontal surfaces such as floors and tabletops. Vuforia Engine has major feature categories, which are images and objects. (Table II and III) [17]

\section{A. Images}

Image targets represent content overlay onto 2D images that Vuforia Engine can detect and track. The Vuforia Engine will detect and track the natural features found in the 2D images by comparing these natural features to a known resource database. Once the image target is detected, it will display content overlaid onto 2D images. A multi-target consists of more than one image target in a determined geometric arrangement. This target enables the entire image targets of a multi-target object to be tracked at the same time. Finally, Cylinder Targets enable detection and tracking of images rolled into cylindrical and conical shapes. Image targets, multi-target, and cylinder targets created by the Vuforia target manager can use JPG or PNG images in RGB or grayscale. The size of the input images must $2 \mathrm{MB}$ or less.

TABLE II: TARGET TYPES IN AN IMAGE FEATURE

\begin{tabular}{l|l|l|l}
\hline \multicolumn{1}{c}{ Target types } & Image targets & Multi targets & Cylinder targets \\
\hline $\begin{array}{l}\text { Recommended } \\
\text { uses }\end{array}$ & $\begin{array}{l}\text { Publications, } \\
\text { packaging, } \\
\text { flat surfaces. }\end{array}$ & $\begin{array}{l}\text { Multiple } \\
\text { publications, } \\
\text { packaging, flat } \\
\text { surfaces. }\end{array}$ & $\begin{array}{l}\text { Product } \\
\text { packaging that is } \\
\text { cylindrical or } \\
\text { conical. }\end{array}$ \\
\hline Target source & Planar images. \\
\hline $\begin{array}{l}\text { Tools for creating } \\
\text { data }\end{array}$ & Vuforia target manager. \\
\hline Data limitations & JPG or PNG the size of images must 2 MB or less. \\
\hline $\begin{array}{l}\text { Supported } \\
\text { environments }\end{array}$ & $\begin{array}{l}\text { The surfaces of the object should be evenly lit. Indoor } \\
\text { scenarios generally work well. }\end{array}$ \\
\hline \hline
\end{tabular}

\section{B. Objects}

TABLE III: TARGET TYPES IN AN OBJECT FEATURE

\begin{tabular}{l|l|l}
\hline \hline \multicolumn{1}{c|}{ Target types } & \multicolumn{1}{c}{ Object recognition } & \multicolumn{1}{c}{ Model targets } \\
\hline $\begin{array}{l}\text { uses } \\
\text { Target source }\end{array}$ & $\begin{array}{l}\text { Toys, products, } \\
\text { complex geometries }\end{array}$ & $\begin{array}{l}\text { Toys, products complex } \\
\text { to large-scale }\end{array}$ \\
\hline $\begin{array}{l}\text { Tools for } \\
\text { creating data }\end{array}$ & $\begin{array}{l}\text { 3D CAD model or a 3D } \\
\text { scan of the object. }\end{array}$ \\
\hline Data limitations & $\begin{array}{l}\text { - Object Data (*OD). } \\
\text { - Objects fit on a } \\
\text { tabletop and found } \\
\text { indoors }\end{array}$ & $\begin{array}{l}\text { Model target generator } \\
\text { (MTG) }\end{array}$ \\
\hline $\begin{array}{l}\text { Collada, FBX, and JT. } \\
\text { - Have a maximum of } \\
\text { 400,000 polygons }\end{array}$ \\
environments & $\begin{array}{l}\text { The surfaces of the object should be evenly lit and } \\
\text { not contain shadows caused by other objects or } \\
\text { people. }\end{array}$ \\
\hline \hline
\end{tabular}

Object Recognition can be used to build rich and interactive experiences with $3 \mathrm{D}$ objects. It has been designed to work with toys and other consumer products that can fit on a tabletop and are found indoors, for example augmenting 3D content to make toys come to life, or overlaying a user manual on top of a consumer electronics device. Model targets enable recognition and tracking of particular objects in the real world based on the shape of the object by using pre-existing 3D models. A wide variety of objects can be used as model targets, from home appliances and toys, to vehicles, to large-scale industrial equipment and even architectural landmarks. For both object recognition and model targets, objects taken as targets must not be deformable or malleable and have no shiny surfaces.

\section{Forensic Medicine Case Study: Drowning}

This section describes the current student studies for forensic medicine in the case of drowning.

Forensic medicine study in the Faculty of Medicine Thammasat University uses a passive mannequin and creates a simulation crime scene. Students are divided into 4 groups to study each scenario and present. Four situations that are always examined are as follows: drowning, shooting and a falling motorcycle, stabbing, and shooting disguised as a suicide. For this research, the use of an AR application in the case of drowning was selected due to it being the number one cause of death for Thai children under 15 years old, an average of 1.5 people per day. [18], and maybe the most common situation. Future work may include a study in other circumstances.

From the study of procedures and methods of postmortem examination in the case of death from drowning [5], [19] there are the following sequence of processes.

Step 1: Crime scene investigation is to collect scene markers, such as general corpse characteristics, the relationship between the corpse and the surrounding area by taking a picture and notes.

Step 2: Rigor mortis and livor mortis are the main factors used in determining the time of death. Rigor mortis is a stiffening of the body after death. Rigor mortis investigation is to estimate the time of death. Typically, the rigor mortis begins about 2-4 hours after death and there is full rigor mortis for 6-12 hours [20]. The investigated positions are shown in Fig. 2.

- Jaw: The method of test is to pull the jaw down with the other hand holding the face or nose.

- Neck: The method of test is to rotate or bend up-down.

- Elbow: The method of test is to move by folding the elbow.

- Finger: The method of test is to move by bending fingers and stretching fingers.

- Hip: The method of test is for the investigator to use one hand to hold the hip, and the other hand to hold the groin or calf, so that the hips are flexed.

- Knee: The method of test is to bend the knee.

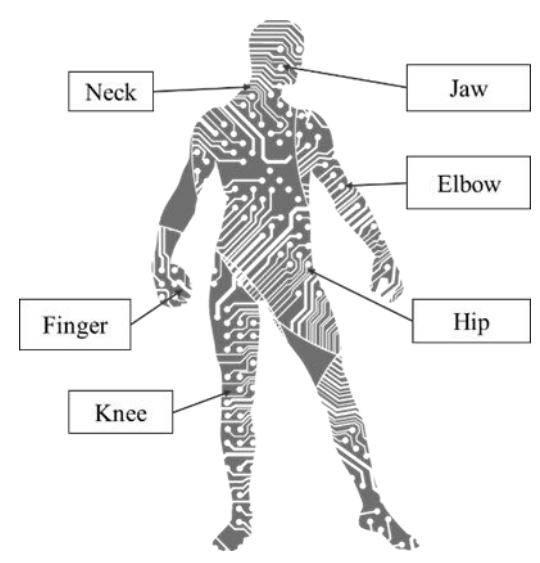

Fig. 2. The positions for rigor mortis investigation. 
Step 3: Livor mortis is a reddish-purple coloration in the lowest part of the body due to the fall of red blood cells according to gravity. Livor mortis gradually occurs reaching the maximum coloration at 8-12 hours after death. After that, if the body is moved to a different posture, the livor mortis remained fixed. It can be tested by using a finger to press at the position of the livor mortis. If livor mortis is not fixed, the position will be pale white for just a moment, and when released, a dark red color will appear. If livor mortis does stay, the position will not appear pale white.

\section{COMPARISON OF Vuforia ENGine FeAtures}

This section compares various Vuforia features based on the different requirements in the detection and display of each step followed in Table IV.

Based on the requirement of step 1, crime scene investigation, the need for this step is when the camera detects a mannequin, the demonstration of a crime scene must appear. Therefore, this step requires a database that is a 3D object and large-scale.

Based on the requirement of step 2, rigor mortis investigation, the camera must detect the target in the position specified on the mannequin. The application will show how to investigate the rigor mortis. By examining the neck, elbow, hip and knee positions, a database must be for 2D and flat surfaces. There is one target at each position and one target detected at a time. The jaw and finger positions are not flat enough for 2D targets; therefore, this position requires a database that is a $3 \mathrm{D}$ object in large-scale for jaw, and normal size for fingers.

Based on the requirement of step 3, livor mortis investigation after completing step 2, the application must guide a medicine student to flip over a mannequin. After that, the target attached to the back of the mannequin will be seen, so the required database for this step is a $2 \mathrm{D}$ target that has flat surfaces.

TABLE IV: COMPARISON BASED ON THE REQUIREMENTS OF EACH STEP FOR STUDYING FORENSIC MEDICINE IN THE CASE OF DROWNING

\begin{tabular}{c|l|c|c|c|c|c}
\hline \hline \multirow{4}{*}{} & \multirow{2}{*}{ Step } & \multicolumn{5}{|c}{ Types of features } \\
\hline & \multicolumn{2}{|c|}{ Image features } & \multicolumn{2}{c}{ Object features } \\
\hline & & \multirow{4}{*}{1} & & & \\
\hline \multirow{4}{*}{1} & 3D Recognition & - & - & - & $\checkmark$ & $\checkmark$ \\
\hline & $\begin{array}{l}\text { Large-scale 3D } \\
\text { object }\end{array}$ & - & - & - & - & $\checkmark$ \\
\hline \multirow{4}{*}{2} & $\begin{array}{l}\text { 3D Recognition at } \\
\text { large-scale }\end{array}$ & - & - & - & - & $\checkmark$ \\
\hline & 3D Recognition & - & - & - & $\checkmark$ & $\checkmark$ \\
\hline & $\begin{array}{l}\text { 2D Recognition of } \\
\text { flat surfaces }\end{array}$ & $\checkmark$ & $\checkmark$ & - & - & - \\
\hline & $\begin{array}{l}\text { Detect 1 target at a } \\
\text { time }\end{array}$ & $\checkmark$ & - & - & - & - \\
\hline \multirow{4}{*}{3} & 2D Recognition & $\checkmark$ & $\checkmark$ & $\checkmark$ & - & - \\
\hline & Flat surfaces & $\checkmark$ & $\checkmark$ & - & - & - \\
\hline & $\begin{array}{l}\text { Detect 1 target at a } \\
\text { time }\end{array}$ & $\checkmark$ & - & - & - & - \\
\hline \hline
\end{tabular}

\section{RESULTS AND DISCUSSION}

From the result of comparing Vuforia features based on the different requirements in the detection and display of each step, we found that the suitable feature for step 1 was the model targets in the object features because all requirements were met. Also, it was able to detect 3D objects at a large-scale. For step 2, there are 2 parts. First, for a section that requires a 2D database for the neck, elbow, hip, and knee image targets, an image feature is more appropriate because this part does not have a distinctive feature. Second, for the section that requires a 3D database for the jaw and finger, the model target in the object feature is more suitable, because this part has a distinctive feature but has a large-scale size which the object target does not support. For step 3, a feature that can detect 2D targets on a flat surface and 1 target at a time is required. The feature that can respond to all the requirements is an image target. Therefore, the selection of the features for the development of AR applications for forensic medicine study of drowning cases must be a combination of more than one suitable feature as presented in Table V.

From the research of Hirosuke Horii and Yohei Miyajima [11], they developed using the ARToolKit SDK, it is not suitable for this research because the ARToolKit SDK limits to only 2D object tracking. The research of Maria Concetta Botrugno et al. [12] developed using Wikitude SDK. According to the ThinkMobiles study which is the biggest marketplace of IT companies and software products, it was found that the best AR SDK is Wikitude SDK as well. However, when studied and compared using the conditions for applying to forensic medicine study, it was found that it had less recognition stability of immovable markers than Vuforia SDK. The most suitable SDK for use in forensic medicine education is Vuforia SDK, which has many beneficial features

TABLE V: THE TyPES of FEATURES SUITABLE FOR THE DROWNING CASE STUDY

\begin{tabular}{|c|c|c|c|c|c|}
\hline \multirow[b]{3}{*}{ Step } & \multicolumn{5}{|c|}{ Types of features } \\
\hline & \multicolumn{3}{|c|}{ Image features } & \multicolumn{2}{|c|}{ Object features } \\
\hline & 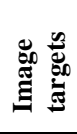 & 鸹总 & 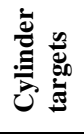 & 总 & 司 \\
\hline $\begin{array}{l}\text { step 1: } \\
\text { crime scene } \\
\text { investigation }\end{array}$ & - & - & - & - & $\checkmark$ \\
\hline $\begin{array}{l}\text { step 2: } \\
\text { rigor mortis } \\
\text { investigation }\end{array}$ & $\checkmark$ & - & - & - & $\checkmark$ \\
\hline $\begin{array}{l}\text { step 3: } \\
\text { livor mortis } \\
\text { investigation }\end{array}$ & $\checkmark$ & - & - & - & - \\
\hline
\end{tabular}

After that, we experimented with creating apps using both image target and model target features. For step 1 we used a model target feature with the database as mannequin generated by model target Generator (MTG) in Vuforia SDK. When the app is opened, the camera is moved to find the model that matches the existing database in order. After that, the content is displayed as in Fig. 3. 


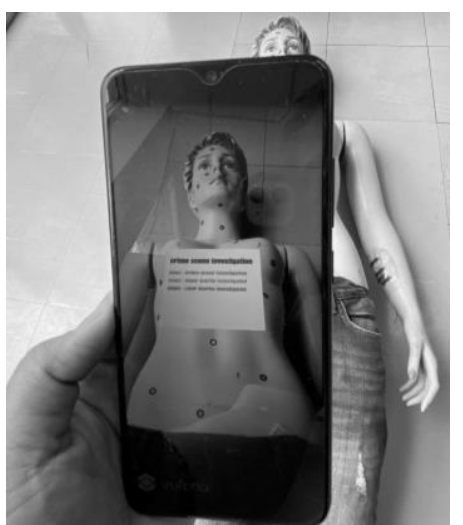

Fig. 3. AR application operation in step1 that uses the model target feature of content rendering, after having detected the model that matches the existing database.

For step 2 there are more than 1 suitable feature, which are jaws and fingers using the model target feature but neck, elbow, hip, and knee using the image target feature. The example shows model targets in the form of fingers, as shown in Fig. 4. (a) and image targets in the form of the neck, as shown in Fig. 4. (b).

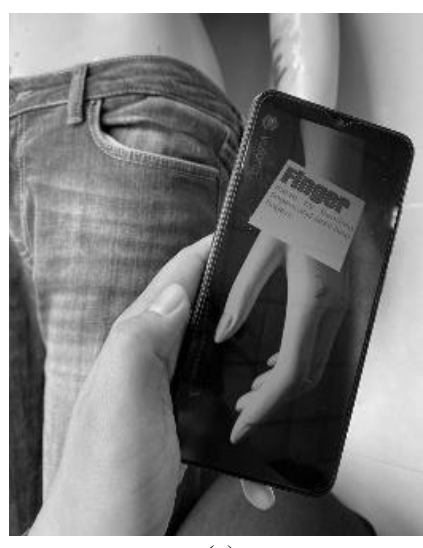

(a)

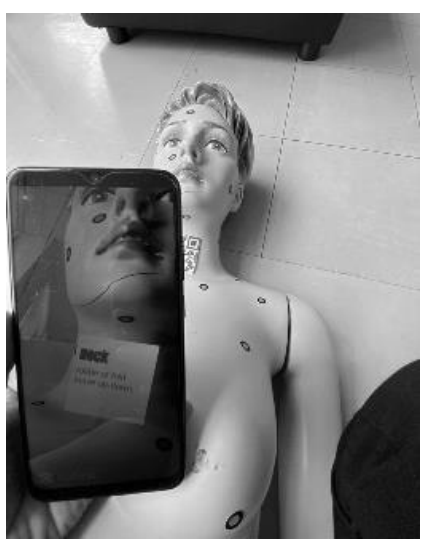

(b)
Fig. 4. Example AR application operation in step 2 (a) is content rendered after detecting the model finger that matches the existing database and (b) is content rendered after detecting the QR code that is attached to the neck of the mannequin.

For step 3 use image target feature with the database as QR code generated by target manager in Vuforia SDK. The QR code is attached to the back of the mannequin. When turning over the mannequin and scanning, the content will appear as in Fig. 5.

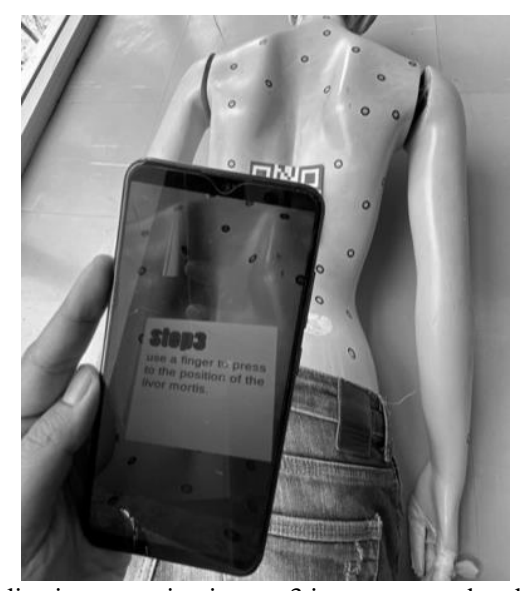

Fig. 5. AR application operation in step 3 is content rendered after detecting the QR code that is attached to the back of the mannequin.

\section{CONCLUSION}

This study can conclude as follows:

- To create an AR system for teaching Forensic Medicine, a suitable type of AR SDK is Vuforia SDK.

- The Vuforia features that are suitable for studying drowning are the model targets in the object features and the image targets in the image features.

\section{CONFLICT OF INTEREST}

The authors declare no conflict of interest.

\section{AUTHOR CONTRIBUTIONS}

Wanwanut Boongsood conducted the research; Krittyaporn Tongprasom collected and analyzed the data; Woramon Boongsood and Tossanai Pipatchotitham gave the guidance on the forensic aspects; all authors had approved the final version.

\section{ACKNOWLEDGMENT}

This research was funded by Suranaree University of Technology.

\section{REFERENCES}

[1] P. Nilthongkum, Civil and Criminal Procedure Code, 4th ed. Thailand: Athataya Milennuim, 2018, pp. 442-448.

[2] Medical Competency Assessment Criteria for National License 2012. [Online]. Available: https://www.tmc.or.th/file_08062012.pdf

[3] Department of Forensic Medicine. [Online]. Available: https://www.si.mahidol.ac.th/annualreport/2015/files/325.pdf

[4] H. C. Black, Black's Law Dictionary, 6th ed. ST. Paul, Minn, West Publishing Co, 1990, pp. 648-649.

[5] A. Tangsermkijsakul, Forensic Medicine, Forensic Doctor, Thammasat University Hospital, 2018.

[6] H. Ha and J. Hong, "Augmented reality in medicine," Hanyang Medical Reviews, 2016, vol. 36, no. 4, pp. 242-247.

[7] L. F. S. Cardoso, F. C. M. Q. Mariano, and E. R. Zorzal, "A survey of industrial augmented reality,” Comp. Industrial. Eng. Elsevier, vol. 139, pp. 1-12, January 2020.

[8] K. Lee, "Augmented reality in education and training," TechTrends, vol. 56, no. 2, pp. 13-21, February 2012.

[9] M. Akçayıra and G. Akçayırb, "Advantages and challenges associated with augmented reality for education: A systematic review of the literature," Educational Research Review, Elsevier, vol. 20, pp. 1-11, November 2016.

[10] F. Liarokapis, N. Mourkoussis, M. White, J. Darcy, M. Sifniotis, P. Petridis, A. Basu, and P. F. Lister, "Web3D and augmented reality to support engineering education," World Trans. on Engineering and Technology Education. vol.3, no.1, pp. 11-14, 2014.

[11] H. Horii and Y. Miyajima, "Augmented reality-based support system for teaching hand-drawn mechanical drawing," in Proc. 13th International Educational Technology Conference, pp. 182-189, 2013.

[12] M. C. Botrugno, G. D'Errico, and L. T. Paolis, "Augmented reality and UAVs in archaeology: development of a location-based AR application," in Proc. 4th International Conference on Augmented Reality, Virtual Reality and Computer Graphics, pp. 261-270, 2017.

[13] Y. Lee and J. Choi, "Tideland animal AR: Superimposing 3D animal models to user defined targets for augmented reality game," International journal of Multimedia and Ubiquitous Engineering, vol. 9, no. 4, pp. 343-348, 2014.

[14] L. Johnson, A. Levine, R. Smith, and S. Stone, The 2010 Horizon Report, Austin, Texas: The New Media Consortium, pp. 21-24.

[15] D. Amin and S. Govilkar, "Comparative study of augmented reality SDKs," International Journal on Computational Science and Applications, vol. 5, no. 1, pp. 11-26. 2015.

[16] Best AR SDK for Development for iOS and Android. [Online]. Available: https://thinkmobiles.com/blog/best-ar-sdk-review

[17] Vuforia Developer Library. [Online]. Available: https://library.vuforia.com/getting-started/overview.html 
[18] The Situation of Drowning Children in Thailand 2019. [Online]. Available:

http://www.thaincd.com/2016/mission/documents-detail.php?id=1379 0\&tid=37\& gid $=1-027$

[19] D. N. Vieira, "Diagnostic of drowning in forensic medicine," in Intech Open Access Books, A. Farrugia and B. Ludes, Ed., 2011, pp. 53-58.

[20] D. D. Maio and V. J. M. D. Maio, Forensic Pathology, 2nd ed., CRC Press, 2001.

Copyright $\odot 2021$ by the authors. This is an open access article distributed under the Creative Commons Attribution License which permits unrestricted use, distribution, and reproduction in any medium, provided the original work is properly cited (CC BY 4.0).

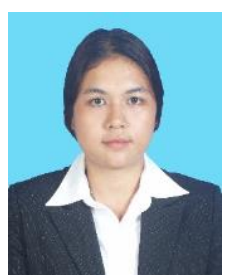

Krittiyaporn Tongprasom received the B.Eng. degree in manufacturing engineering from Suranaree University of Technology Thailand in 2015.

From 2016 to 2017, she worked as a teaching assistant at the School of Manufacturing Engineering, Suranaree University of Technology, and from 2017 to present. She is a master's student at Suranaree University of Technology and her research interests are AR applications

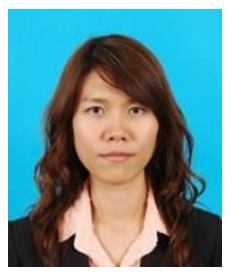

Wanwanut Boongsood received the Ph.D. degree in engineering from the University of Liverpool, Liverpool, UK.

She was with Mitsubishi Electric Automation (Thailand) as a design engineer for six years. In 2006, she joined Suranaree University of Technology, Nakhon Ratchasima, Thailand, where she is currently an assistant professor at the School of Manufacturing
Engineering. Her research interests include (but not limit to) optimization, design for manufacturing and assembly, and advanced manufacturing.

Asst. Prof. Boongsood has ASME certification as a Technologist Level GD\&T Professional.

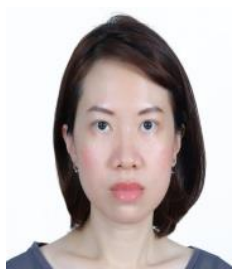

Woramon Boongsood graduated from the Faculty of Medicine, Thammasat University, Thailand in 2007 then received a diploma of Thai board of forensic medicine, Faculty of Medicine, Siriraj Hospital, Thailand in 2013, bachelor's degree of laws, Khon Kaen University, Thailand in 2017.

She starts working as a forensic physician since received the diploma in 2013, current working is forensic physician in Thammasat University Hospital, Thailand. Her research interests are forensic medicine and medical laws and ethics.

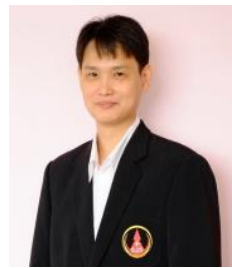

Tossanai Pipatchotitham received a doctor of medicine from Mahidol University Thailand in 2000 and received a diploma of Thai board of forensic medicine in 2006.

From 2006 to 2013, he worked as a forensic physician at Nakhonpathom hospital and Thammasat hospital. From 2014 to present, he is a lecturer at the Faculty of Medicine, Thammasat University, and his research interests are forensic medicine and medical education. 